\title{
Low Absorption Reticulocytes to Total Reticulocytes Ratio Measurement
}

National Cancer Institute

\section{Source}

National Cancer Institute. Low Absorption Reticulocytes to Total Reticulocytes Ratio

Measurement. NCI Thesaurus. Code C116191.

The determination of the ratio of low absorption reticulocytes compared to total reticulocytes present in a sample. The measurement may be expressed as a ratio or percentage. 